\title{
The remote exercise monitoring trial for exercise-based cardiac rehabilitation (REMOTE-CR): a randomised controlled trial protocol
}

Ralph Maddison 1*, Jonathan C Rawstorn ${ }^{1,2}$, Anna Rolleston ${ }^{3}$, Robyn Whittaker ${ }^{1}$, Ralph Stewart ${ }^{4}$, Jocelyne Benatar ${ }^{4}$, lan Warren ${ }^{5}$, Yannan Jiang ${ }^{1}$ and Nicholas Gant ${ }^{2}$

\begin{abstract}
Background: Exercise is an essential component of contemporary cardiac rehabilitation programs for the secondary prevention of coronary heart disease. Despite the benefits associated with regular exercise, adherence with supervised exercise-based cardiac rehabilitation remains low. Increasingly powerful mobile technologies, such as smartphones and wireless physiological sensors, may extend the capability of exercise-based cardiac rehabilitation by enabling real-time exercise monitoring for those with coronary heart disease. This study compares the effectiveness of technology-assisted, home-based, remote monitored exercise-based cardiac rehabilitation (REMOTE) to standard supervised exercise-based cardiac rehabilitation in New Zealand adults with a diagnosis of coronary heart disease.
\end{abstract}

Methods/Design: A two-arm, parallel, non-inferiority, randomised controlled trial will be conducted at two sites in New Zealand. One hundred and sixty two participants will be randomised at a 1:1 ratio to receive a 12-week program of technology-assisted, home-based, remote monitored exercise-based cardiac rehabilitation (intervention), or an 8-12 program of standard supervised exercise-based cardiac rehabilitation (control).

The primary outcome is post-treatment maximal oxygen uptake $\left(\mathrm{V}_{2} \mathrm{O}_{2} \mathrm{~m}\right)$. Secondary outcomes include cardiovascular risk factors (blood lipid and glucose concentrations, blood pressure, anthropometry), self-efficacy, intentions and motivation to be active, objectively measured physical activity, self-reported leisure time exercise and health-related quality of life. Cost information will also be collected to compare the two modes of delivery. All outcomes are assessed at baseline, post-treatment, and 6 months, except for $\dot{\mathrm{V}}_{2}$ max, blood lipid and glucose concentrations, which are assessed at baseline and post-treatment only.

Discussion: This novel study will compare the effectiveness of technology-supported exercise-based cardiac rehabilitation to a traditional supervised approach. If the REMOTE program proves to be as effective as traditional cardiac rehabilitation, it has potential to augment current practice by increasing access for those who cannot utilise existing services.

Trial registration: Australian New Zealand Clinical Trials Registry Study ID number: ACTRN12614000843651. Registered 7 August 2014

Keywords: mHealth, Telemonitoring, Remote sensing technology, Exercise training, Peak oxygen uptake, Coronary heart disease, Smartphone, App

\footnotetext{
* Correspondence: r.maddison@auckland.ac.nz

${ }^{1}$ National Institute for Health Innovation, University of Auckland, Private Bag

92019, Auckland 1142, New Zealand

Full list of author information is available at the end of the article
}

\section{Biomed Central}

(c) 2014 Maddison et al.; licensee BioMed Central Ltd. This is an Open Access article distributed under the terms of the Creative Commons Attribution License (http://creativecommons.org/licenses/by/4.0), which permits unrestricted use, distribution, and reproduction in any medium, provided the original work is properly credited. The Creative Commons Public Domain Dedication waiver (http://creativecommons.org/publicdomain/zero/1.0/) applies to the data made available in this article, unless otherwise stated. 


\section{Background}

Cardiovascular diseases (CVD) are the leading cause of death worldwide - 30\% (16.7 million) of total deaths globally [1]. The largest proportion of CVD mortality is attributed to coronary heart disease (CHD) [2,3], the prevalence of which is projected to increase $16.6 \%$ by 2030 [4]. Thus there is an increasing need for secondary prevention strategies to reduce the impact of CHD. Cardiac rehabilitation $(\mathrm{CR})$ is a complex secondary prevention intervention that aims to optimise cardiovascular disease risk reduction, promote the adoption and adherence of healthy behaviours and reduce disability among those with established CHD [5]. Secondary prevention guidelines recommend a multifaceted CHD risk management approach [6-8]; however exercise is consistently identified as an integral component of CR [5,9-11], and its potential as a risk modification strategy extends beyond the effects of physical inactivity alone.

Numerous beneficial cardiovascular and metabolic adaptations enable exercise to concurrently target several established CHD risk factors including blood pressure, blood lipid profile, glucose metabolism, weight status and body composition [12]. Moreover, a Cochrane review [13] reported $13 \%(\mathrm{RR}=0.87,95 \% \mathrm{CI} 0.75,0.99)$ and $26 \%$ $(\mathrm{RR}=0.74,95 \% \mathrm{CI} 0.63,0.87)$ reductions in all-cause and cardiovascular mortality, respectively, following exerciseonly CR and comprehensive CR incorporating an exercise component. These findings are supported by several other meta-analyses [14-16].

Despite its documented benefits CR adoption is low in many countries $[9,17,18]$, including New Zealand $[19,20]$. Exercise adherence is also poor, with up to $36 \%$ attrition from supervised programs [21-24]. Factors commonly associated with sub-optimal participation include ill health, domestic responsibilities, and difficulty accessing supervised programs $[25,26]$. Low accessibility is of particular concern as it is associated with higher levels of cardiac morbidity and mortality [27]. A recent HEART journal editorial [28] concluded that CR should not only focus on CHD risk factor modification and medication adherence but should also offer a range of different delivery options for people according to their preferences and needs to address the low levels of participation. One such approach that has been investigated for risk factor modification has been the use of telehealth, which involves telephone, internet, and videoconference communication between patient and health-care provider.

A systematic review of 11 telehealth trials $(n=3145)$ showed significant improvements on CHD risk factors including exercise adherence and volume, total cholesterol, high density lipoprotein cholesterol and systolic blood pressure [29]. While these findings support telehealth, research has been limited to land-based telephone, internet and videoconferencing technologies that confine participants to fixed locations. As such there is a need to explore technologies that support increased program flexibility. Mobile technologies, including the internet are therefore gaining increased research attention as an alternative approach to support behaviour change, clinical improvement, and improved social functioning [30].

Emerging evidence to date for mobile interventions for delivering healthcare and improving disease selfmanagement (mHealth) is promising [30]. A number of systematic reviews support the delivery of mobile phone text messaging interventions [31-33] for achieving behaviour change across a range of behaviours and chronic conditions such as diabetes and asthma.

In terms of $\mathrm{CHD}$, the recently completed HEART randomised controlled trial $(n=171)$ demonstrated a mobile phone text messaging and internet intervention was effective and cost-effective for increasing leisure time physical activity and walking, but was not effective for increasing maximal oxygen uptake over and above usual care in people with CVD at 6 months [34]. Compared to the usual care control group, the HEART intervention also significantly increased participants' health-related quality of life (physical health domain), self-efficacy and motivation to be physically active. Structured exit interviews conducted with those who were randomised to the intervention showed the HEART intervention was well received, had positive effects on participant's physical activity levels, and was not considered burdensome. Most (93\%) participants read all or most of their text messages [35]. Whilst this trial demonstrated the feasibility and effectiveness of a text messaging intervention to increase physical activity levels, improvement is needed to ensure interventions achieve positive impacts on exercise capacity and other CVD risk factors. Such improvements include closer exercise monitoring to ensure participants meet the required frequency, intensity and duration to realise beneficial physiological adaptations.

Increasingly powerful mobile technologies, such as smartphones and wireless physiological sensors, may extend the capability of mHealth exercise-based CR (exCR) by enabling real-time remote exercise monitoring for those with CVD. The feasibility of remotely monitored exCR was recently demonstrated using a smartphone, ECG sensor and GPS receiver [36]. A six-week remote exCR program improved walking performance (comparable to traditional exCR), cardiac depression and physical health-related quality of life. Furthermore, system usability and reliability were rated highly by participants. These encouraging results demonstrate the feasibility of remote exCR; however, a randomised controlled trial is required to determine the benefits and harms associated with this approach. 
Aim

To compare the effectiveness of technology-assisted, home-based, remotely monitored exCR (REMOTE) to standard supervised exCR in New Zealand adults with a diagnosis of CHD.

\section{Hypotheses}

The primary hypothesis is that the REMOTE program will be as effective at increasing exercise capacity compared to standard exCR. Secondary hypotheses are; the REMOTE program will result in similar improvements in other cardiovascular risk factors (blood lipid and glucose concentration, blood pressure, anthropometry) compared to standard exCR. The REMOTE program will result in greater exercise adherence compared to standard exCR.

\section{Methods/Design}

The study design is a single-blinded, two-arm, parallel, randomised controlled non-inferiority trial. Given the established effectiveness of supervised exCR [12] the REMOTE program is unlikely to result in a substantially greater improvement in exercise capacity; however, it's advantages in terms of greater reach and participant adherence highlight the appropriateness of a non-inferiority trial design. The protocol is in accord with the SPIRIT 2013 statement $[37,38]$, and the intervention is described according to the CONSORT-EHEALTH checklist [39].

\section{Eligibility and recruitment}

Eligible participants are adults aged 18 years or more, with a diagnosis of CHD (angina, myocardial infarction, percutaneous coronary intervention or coronary revascularisation) within the previous six months. Participants are current outpatients who have been clinically stable for at least six weeks, are able to perform exercise, and can understand and write English. A Motorola (Moto G) smart phone is available on loan to participants in the REMOTE group. Participants who have been admitted to hospital with heart disease within the previous six weeks, have terminal cancer, are contraindicated for maximal exercise testing, have significant exercise limitations other than CHD, currently meet the recommendations for regular physical activity (150 min/week moderate to vigorous) [40], are currently participating in a supervised exercise program (including exCR), have a pacemaker or implantable cardioverter-defibrillator, or have contraindications for maximal exercise testing are excluded.

Eligible participants are identified by research nurses or research assistants from a large metropolitan hospital in Auckland, New Zealand (population 1.6 million) prior to discharge, through outpatient clinics and existing databases, as well as existing community CR education sessions. Those agreeing to participate are screened for eligibility and provided a study pack, which includes a participant information sheet and consent form. Contact details of interested participants are sent to the research team. Participants identified in hospital and through outpatient clinics are telephoned approximately one month after discharge or one week after initial contact, respectively, to confirm their interest in the study and schedule a baseline assessment. Eligible participants are also recruited by a research staff at an existing CR clinic in the Bay of Plenty, New Zealand. These participants have been discharged from hospital, are eligible to participate in CR but have not yet enrolled in a program. Interested participants are given a study pack and a baseline assessment is scheduled.

\section{Sample size calculation}

The target sample size of 162 participants (81 per group) will provide $80 \%$ power at $2.5 \%$ level of significance (one-sided) to show that the REMOTE and standard exCR programs do not differ by more than $\mathrm{ml} \cdot \mathrm{kg}^{-1} \cdot \mathrm{min}^{-1}$ on peak oxygen uptake $\left(\dot{\mathrm{VO}}_{2} \mathrm{max}\right)$. This sample size is based on the assumption the standard exCR program will result in an increase of $2.4 \mathrm{ml} \cdot \mathrm{kg}^{-1} \cdot \mathrm{min}^{-1}(\mathrm{SD}=2.7)$ in $\dot{\mathrm{VO}}{ }_{2} \mathrm{max}$, and has been inflated to allow for $10 \%$ loss to follow up [12]. The non-inferiority margin was chosen because it is clinically significant and is associated with lower CV-mortality $[41,42]$.

\section{Ethics approval}

Ethical approval for the trial was received from the University of Auckland Human Participants Ethics Committee (011021). Approval was also obtained from the Metropolitan Hospital's Research Review Board.

\section{Randomisation and blinding}

After written consent is obtained, baseline assessment is completed and then participants are randomised using sealed sequential, opaque envelopes. Participants are randomly allocated to either the control (traditional exCR) or intervention (REMOTE) arms at a 1:1 ratio, stratified by study site and sex. The allocation sequence is overseen by the project statistician (YJ). Assessors of the primary outcomes are blind to treatment allocation; however participants are not blind.

\section{Intervention}

The REMOTE intervention is delivered over 12 weeks and comprises a personalised exercise prescription, real-time remote exercise monitoring, and behavioural support to increase exercise adherence (goal setting, exercise scheduling, overcoming barriers), delivered via smartphone. The intervention aims to have individuals participate in moderate to vigorous aerobic-based exercise for at least $30 \mathrm{mi}$ nutes (preferably more), most days $(\geq 5)$ of the week, in 
line with current recommendations [40] and American College of Sports Medicine (ACSM) guidelines [43]. Specific details are provided below.

\section{Exercise prescription}

An individualised exercise prescription, based on personal preferences and current exercise capacity, is a core component of the intervention. Following ACSM guidelines for exercise in cardiac patients [43] participants are provided with a weekly prescription detailing exercise duration, frequency and intensity, via a smartphone application (app) designed for this study. The prescribed exercise intensity is sufficient to induce a "training effect", yet below a metabolic load that evokes abnormal clinical signs or symptoms. Exercise duration is increased according to symptoms and clinical status. Exercise intensity is increased gradually as tolerated [44]. Progression of exercise prescription components occurs in the following order: duration, frequency, then intensity [44]. Participants are taught and encouraged to use ratings of perceived exertion (RPE) and the heart rate reserve method (HRR) to achieve the desired intensity. During early stages the level of intensity targets an RPE of 11 to 13 ("fairly light" and "somewhat hard"; 6-20 scale) [45] and/or $40 \%$ to $50 \%$ HRR. During the latter stages the level of intensity targets an RPE of 13 to 15 ("somewhat hard" to "hard") and/or $55 \%$ to $65 \%$ HRR. The preferred mode of exercise is walking, although participants are able to choose other modes (e.g. cycling, rowing) if preferred.

\section{Remote monitoring}

During pre-defined time windows (e.g. 06:00-11:00) participants connect to the remote exercise monitoring system, which permits a remotely-located exercise physiologist to monitor their location, distance, speed, heart rate, respiratory rate, training load and single-lead ECG in real-time; provide real-time feedback and support via participants' smartphone (including alerts, messages or telephone calls); respond to adverse events if necessary; provide postexercise feedback; and modify participants' exercise prescription as required. Participants can be monitored in any environment with an active broadband connection (mobile, Wi-Fi, Bluetooth).

The REMOTE system, comprising a physiological sensing device, smartphone and web apps, and a middleware platform, supports simultaneous monitoring of multiple participants. Participants are loaned a BioHarness 3 (Zephyr Technologies, USA) physiological sensing device to wear during exercise. The BioHarness enables measurement of a comprehensive range of physiological parameters required for monitoring exercise performance. Bluetooth connectivity permits transmission of data to smartphones. The system including the Zephyr device, smartphone (Android) app, and the Odin middleware platform has been tested for reliability and validity (Rawstorn J, Gant N, Warren I, Doughty R, Lever N, Poppe K: Measurement and data transmission validity of a multi-biosensor system for real-time remote exercise monitoring among cardiac patients, forthcoming). The Odin middleware platform is an off-the-shelf solution that provides reliable communication, minimises data usage cost and maximises device battery life [46]. The smartphone app collects and transmits physiological data to a remotely located web server in real-time. The web app displays these data in remote locations, and enables real-time provision of feedback to moderate participants' exercise behaviour.

\section{Support and strategies to facilitate exercise adherence}

Messages outlining key behaviour change strategies are sent to participants via the smartphone by the exercise physiologist. Three messages per week are sent for the 12 week intervention period. The program is grounded in self-efficacy theory $[47,48]$, which is the most examined psychological variable within the cardiac setting. Behaviour change strategies focus on increasing confidence and motivation to exercise, overcoming barriers to being physically active, scheduling exercise into daily life, goal setting, and enhancing social support and networks to be active. In addition, features on the smartphone app allow participants to review their exercise performance and assess progress toward personalised goals.

\section{Control}

The active control group receive an 8-12 week program of supervised exercise, delivered at Auckland or Tauranga CR clinics. Supervised exercise sessions are offered two-three times per week by trained exercise scientists/ nurses. Participants typically complete a 15 -minute warm up, 30-45 minutes of moderate-vigorous intensity aerobic exercise on various exercise modalities (e.g., treadmill, cycle ergometer, rowing machine), and a 5 min cool down. Heart rate, blood pressure, and rating of perceived exertion (RPE) are monitored on a regular basis. Exercise prescription for the control group also adheres to ACSM guidelines for exercise in cardiac patients [43].

\section{Outcome assessments}

All assessments are conducted at the University of Auckland and Tauranga cardiac clinics. Prior to the baseline assessment participants are sent an accelerometer to wear for seven consecutive days. Baseline assessments involve an explanation of study procedures, signed consent and collection of participant-reported secondary outcomes, followed by physical measurements (stature, body mass, body mass index, waist and hip circumference), blood lipid and glucose measurements, and a test of maximal exercise capacity. The baseline assessment 
concludes with randomisation and assignment of participants to the respective study groups.

The primary outcome is maximal oxygen uptake $\left(\dot{\mathrm{V}}_{2} \max \right)$ assessed at baseline and post-treatment. An individualised exercise testing protocol is used to assess $\dot{\mathrm{V}}_{2}$ max via respiratory gas analysis. A graded protocol is initiated at a comfortable walking speed and $0 \%$ gradient. The gradient then increases by $1 \%$ every 60 seconds until volitional exhaustion, or the presence of indications for test termination [44]. The target exercise time is 8 to 12 minutes. Individualised walking speeds are replicated at the 13 week follow-up assessment. Participants are encouraged to continue the test until the respiratory exchange ratio (RER) exceeds 1.10, indicative of a maximal aerobic performance. The ACSM guidelines for exercise testing cardiac patients are adhered to [44]. Exercise testing is conducted at the University of Auckland Clinics, Tamaki Campus, and the Tauranga cardiac clinic by trained physiologists. A medical physician is available to deal with any emergencies that may arise.

\section{Secondary outcomes}

All secondary outcomes are assessed at baseline, posttreatment and 6 months, except for blood lipid and glucose concentrations, which are assessed at baseline and post-treatment only. Stature, body mass, waist and hip circumference, and blood pressure are measured using standardised procedures. An electronic sphygmomanometer will be used to assess systolic and diastolic pressure after at least 5 minutes of seated rest. Participants' height will be measured to the nearest $0.1 \mathrm{~cm}$ using a stadiometer, and body mass to the nearest 0.1 kilograms using electronic scales. Body mass index is derived from the weight $(\mathrm{kg})$ divided by height $(\mathrm{m})$ squared. Waist circumference is measured using an anthropometric tape measure placed around the participant's waist at the level of the umbilicus. Hip circumference is measured around the furthest protrusion of the buttocks as seen from a lateral perspective. Waist-hip ratio is calculated according to ISAK protocols [49].

A fingertip blood sample is obtained from participants for analysis of blood lipid and glucose concentration using automated point of care analysers (Cholestech LDX at the Auckland site, CardioChek at the Tauranga site).

Psychological variables including self-efficacy (situational self-confidence), intentions, and motivation to exercise are assessed to determine their potential mediating effect. Task self-efficacy is assessed using a scale adapted from the Self-Efficacy Scale [50]. Participants rate their confidence to perform physical activities for increasing periods of time (i.e., 10, 30, and $60 \mathrm{~min}$ ) at three intensities (i.e., light, moderate, and vigorous). A key is provided to define these levels of intensity. Mean scores are calculated with higher values indicating greater efficacy to perform physical activity for longer duration and greater intensity.

Participants' confidence to exercise in the face of obstacles (barrier efficacy) is assessed using the Barriers Efficacy Scale [50]. Participants rate their confidence to overcome eight common reasons preventing people from participating in exercise sessions (e.g., pain, bad weather) on a scale ranging from $0 \%$ (no confidence at all) to $100 \%$ (completely confident). Mean scores are calculated with higher values indicating greater efficacy to overcome barriers to exercise.

Self-efficacy to follow their exercise prescription is assessed using 9 items. Participants rate their confidence in their ability to follow the prescribed exercise regimen on a scale ranging from $0 \%$ (no confidence at all) to $100 \%$ (completely confident). Mean scores are calculated with higher values indicating greater efficacy to adhere to prescribed exercise.

Intentions to perform physical activity are assessed using two items [51], which ask participants to rate their level of intention to follow their exercise prescription during the next 3 months (e.g. "I definitely intend to follow my exercise prescription"). The items are scored using a seven point Likert scale ranging from 0 (completely disagree) to 7 (completely agree). A mean score from the two items is used to give an overall measure of intention with higher values indicating greater intention to perform physical activity.

Self-determination to exercise is operationalised using the Locus of Causality for Exercise Scale; a reliable and valid three-item self-report measure of the extent to which participants feel they choose to exercise with no sense of coercion [52]. Participants rate how much they agree or disagree with each statement on a seven-item Likert scale from 1 (Strongly disagree) to 7 (Strongly agree) indicating their motivation to perform exercise. Mean scores are calculated with higher values indicating greater self-determination or a more internal perceived locus of causality.

Leisure time exercise is assessed using the Godin Leisure Time Physical Activity Questionnaire (GLTPAQ) [53]. This simple three-item questionnaire has well-established reliability and validity and has been used in patients undergoing $\mathrm{CR}(\mathrm{N}=826)$ [53].

Objective physical activity is assessed using the Actigraph accelerometer (www.theActigraph.com), which is sent to participants to wear for 7 consecutive days. The Actigraph is a small piezoelectric accelerometer and has been validated in healthy and cardiac patients $[54,55]$. Raw data are processed according to accepted procedures [56].

Adherence to the prescribed regimens is assessed by determining the number of sessions attended compared to the number of sessions prescribed. Participants in both programs are encouraged to participate in supervised 
exercise three times per week. Attendance data are collected weekly and summed to determine total attendance (the numerator) compared to total number of sessions prescribed (denominator).

Cost information is collected and includes the cost of each program and direct medical costs (including cost of treatment, primary care, secondary care and over-thecounter medications). The EQ5D [57] is used to obtain a single preference index for calculation of Quality Adjusted Life Year (QALY) to assess cost per QALY for comparison with CR programs. Healthcare utilisation is recorded for adverse events including cardiac events, and other events participants deem likely to be related to their participation in the study (including, but not limited to, musculoskeletal injury).

\section{Statistical analysis}

Statistical analyses will be performed using SAS version 9.2 (SAS Institute Inc. Cary NC) and R version 2.11 (R Foundations for Statistical Computing). Baseline characteristics will be summarised using descriptive statistics. Continuous variables will be described as numbers of observed and missing values, mean, standard deviation, median, minimum and maximum. Categorical variables will be described as frequencies and percentages. Treatment evaluation will be performed on the principle of intention to treat (ITT), using data collected from all randomised participants. Analysis of covariance (ANCOVA) regression model will be used to evaluate the main treatment effect on the primary outcome between the two treatment groups, adjusting for its baseline measure, age, ethnicity and other potential confounding factors (if they are statistically significant at 5\% level). A similar approach will be used for other continuous secondary outcome measures. Logistic regression model will be considered for the analysis of a binary outcome (e.g. meeting physical activity recommendations).

\section{Discussion}

This novel study evaluates a supervised exercise program delivered via a mobile phone and sensor system compared to a traditional model of supervised exCR. Remote monitoring may offer the same benefits as supervised gymbased programs, but is potentially more accessible to a broader range of patients and is cost-effective.

The protocol, in accordance with the SPIRIT statement, incorporates findings from recent mobile and telehealth systematic reviews, with the aim of building on this empirical evidence. The REMOTE-CR trial includes an objective assessment of maximal cardiorespiratory fitness, which is the gold standard measurement following exCR. It also includes objective assessment of physical activity, which was lacking in previous research [34].
The non-inferiority trial design is most suitable because it is unlikely the REMOTE intervention will result in substantially greater improvement in exercise capacity compared to traditional supervised exercise [58]. The non-inferiority margin $\left(\dot{\mathrm{VO}}_{2} 1.25 \mathrm{ml} \cdot \mathrm{kg}^{-1} \cdot \mathrm{min}^{-1}\right)$ is clinically significant and is associated with lower cardiovascular mortality [59].

\section{Competing interests \\ The authors declare that they have no competing interests.}

\section{Authors' contributions}

RM and JR conceived the study, participated in its design and coordination, and helped draft the manuscript. AR, NG, RW and YJ participated in the design of the study. RS and JB provide clinical oversight for the study. IW participated in the design of the study and created the REMOTE software. All authors read and approved the final manuscript.

Sources of support

This is an investigator-initiated study funded by a grant from the Auckland Medical Research Foundation, 1113020. Dr Maddison is supported by a Health Research Council, Sir Charles Hercus Research Fellowship.

\section{Author details}

${ }^{1}$ National Institute for Health Innovation, University of Auckland, Private Bag 92019, Auckland 1142, New Zealand. ${ }^{2}$ Department of Sport and Exercise Science, University of Auckland, Auckland, New Zealand. ${ }^{3}$ The Cardiac Clinic, Tauranga, Bay of Plenty, New Zealand. ${ }^{4}$ Department of Cardiology, Auckland City Hospital, Auckland, New Zealand. ${ }^{5}$ Department of Computer Science, University of Auckland, Auckland, New Zealand.

Received: 29 October 2014 Accepted: 4 November 2014 Published: 28 November 2014

\section{References}

1. World Health Organisation: World Health Statistics 2012. In Book World Health Statistics 2012. (Editor ed.^eds.). City; 2012.

2. Roger VL, Go AS, Lloyd-Jones DM, Benjamin EJ, Berry JD, Borden WB, Bravata DM, Dai S, Ford ES, Fox CS, Fullerton HJ, Gillespie C, Hailpern SM, Heit JA Howard VJ, Kissela BM, Kittner SJ, Lackland DT, Lichtman JH, Lisabeth LD, Makuc DM, Marcus GM, Marelli A, Matchar DB, Moy CS, Mozaffarian D, Mussolino ME, Nichol G, Paynter NP, Soliman EZ, et al: Heart disease and stroke statistics-2012 update: a report from the American Heart Association. Circulation 2012, 125:e2-e220.

3. World Health Organisation: The Global Burden of Disease: 2004 Update. In Book The Global Burden of Disease: 2004 Update. (Editor ed.^eds.). City; 2008.

4. Heidenreich PA, Trogdon JG, Khavjou OA, Butler J, Dracup K, Ezekowitz MD, Finkelstein EA, Hong Y, Johnston SC, Khera A: Forecasting the Future of Cardiovascular Disease in the United States A Policy Statement From the American Heart Association. Circulation 2011, 123:933-944.

5. Balady GJ, Williams MA, Ades PA, Bittner V, Comoss P, Foody JM, Franklin B, Sanderson B, Southard D: Core components of cardiac rehabilitation/ secondary prevention programs: 2007 update: a scientific statement from the American Heart Association Exercise, Cardiac Rehabilitation, and Prevention Committee, the Council on Clinical Cardiology; the Councils on Cardiovascular Nursing, Epidemiology and Prevention, and Nutrition, Physical Activity, and Metabolism; and the American Association of Cardiovascular and Pulmonary Rehabilitation. Circulation 2007, 115:2675-2682.

6. American Association for Cardiovascular and Pulmonary Rehabilitation: Guidelines for Cardiac Rehabilitation and Secondary Prevention Programs. 4th edition. Champaign, III: Human Kinetics; 2004.

7. Leon AS, Franklin BA, Costa F, Balady GJ, Berra KA, Stewart KJ, Thompson PD, Williams MA, Lauer MS: Cardiac rehabilitation and secondary prevention of coronary heart disease: an American Heart Association scientific statement from the Council on Clinical Cardiology (Subcommittee on Exercise, Cardiac Rehabilitation, and Prevention) and the Council on Nutrition, Physical Activity, and Metabolism (Subcommittee on Physical Activity), in collaboration with the American 
association of Cardiovascular and Pulmonary Rehabilitation. Circulation 2005, 111:369-376.

8. Wenger NK, Froelicher ES, Smith LK: Cardiac rehabilitation as secondary prevention. Agency for Health Care Policy and Research and National Heart, Lung, and Blood Institute. Clin Pract Guidelines 1995, 17:1-23.

9. Bethell H, Lewin R, Dalal H: Cardiac rehabilitation in the United Kingdom. Heart 2009, 95:271-275.

10. Graham I, Atar D, Borch-Johnsen K, Boysen G, Burell G, Cifkova R, Dallongeville J, De Backer G, Ebrahim S, Gjelsvik B, Herrmann-Lingen C, Hoes A, Humphries S, Knapton M, Perk J, Priori SG, Pyorala K, Reiner Z, Ruilope L, Sans-Menendez S, Op Reimer WS, Weissberg P, Wood D, Yarnell J, Zamorano JL, Walma E, Fitzgerald T, Cooney MT, Dudina A, Vahanian A, et al: European guidelines on cardiovascular disease prevention in clinical practice: full text. Fourth Joint Task Force of the European Society of Cardiology and other societies on cardiovascular disease prevention in clinical practice (constituted by representatives of nine societies and by invited experts). Eur J Cardiovasc Prev Rehabil 2007, 14(Suppl 2):S1-S113.

11. Stone JA, Cyr C, Friesen M, Kennedy-Symonds H, Stene R, Smilovitch M: Canadian guidelines for cardiac rehabilitation and atherosclerotic heart disease prevention: a summary. Can J Cardiol 2001, 17 Suppl B:3B-30B.

12. Lavie C, J, Milani RV: Cardiac rehabilitation and exercise training in secondary coronary disease prevention. Prog CardiovasC Dis 2011, 53:397-403.

13. Heran BS, Chen JM, Ebrahim S, Moxham T, Oldridge N, Rees K, Thompson DR, Taylor RS: Exercise-based cardiac rehabilitation for coronary heart disease. Cochrane Database Syst Rev 2011, (7):CD001800.

14. Clark AM, Hartling L, Vandermeer B, McAlister FA: Meta-analysis: secondary prevention programs for patients with coronary artery disease. Ann Intern Med 2005, 143:659-672.

15. Lawler PR, Filion KB, Eisenberg MJ: Efficacy of exercise-based cardiac rehabilitation post-myocardial infarction: a systematic review and meta-analysis of randomized controlled trials. Am Heart J 2011 , 162:571-584 e572.

16. Taylor RS, Brown A, Ebrahim S, Jolliffe J, Noorani H, Rees K, Skidmore B, Stone JA, Thompson DR, Oldridge N: Exercise-based rehabilitation for patients with coronary heart disease: systematic review and metaanalysis of randomized controlled trials. Am J Med 2004, 116:682-692.

17. Suaya JA, Shepard DS, Normand SL, Ades PA, Prottas J, Stason WB: Use of cardiac rehabilitation by Medicare beneficiaries after myocardial infarction or coronary bypass surgery. Circulation 2007, 116:1653-1662.

18. Walters DL, Aroney CN, Chew DP, Bungey L, Coverdale SG, Allan R, Brieger D: Variations in the application of cardiac care in Australia. Med J Aust 2008, 188:218-223.

19. Doolan-Noble F, Broad J, Riddell T, North D: Cardiac rehabilitation services in New Zealand: access and utilisation. N Z Med J 2004, 117:U955.

20. Parks D, Allison M, Doughty R, Cunningham L, Ellis CJ: An audit of phase I cardiac rehabilitation at Auckland hospital. N Z Med J 2000, 113:158-161.

21. Ades PA, Maloney A, Savage P, Carhart RL Jr: Determinants of physical functioning in coronary patients: response to cardiac rehabilitation. Arch Intern Med 1999, 159:2357-2360.

22. Bethell HJ: Exercise in cardiac rehabilitation. Br J Sports Med 1999, 33:79-86.

23. Bock BC, Albrecht AE, Traficante RM, Clark MM, Pinto BM, Tilkemeier $P$, Marcus BH: Predictors of exercise adherence following participation in a cardiac rehabilitation program. Int J Behav Med 1997, 4:60-75.

24. Moore SM, Dolansky MA, Ruland CM, Pashkow FJ, Blackburn GG: Predictors of women's exercise maintenance after cardiac rehabilitation. J Cardiopulm Rehabil 2003, 23:40-49.

25. Inglis SC, Clark RA, MCAlister FA, Ball J, Lewinter C, Cullington D, Stewart S, Cleland JG: Structured telephone support or telemonitoring programmes for patients with chronic heart failure. Cochrane Database Syst Rev 2010, (8):CD007228

26. Jones M, Jolly K, Raftery J, Lip GY, Greenfield S: 'DNA' may not mean 'did not participate': a qualitative study of reasons for non-adherence at home- and centre-based cardiac rehabilitation. Fam Pract 2007 24:343-357.

27. Australian Institute of Health and Welfare: Australia's health 2008. In Book Australia's health 2008; 2008. (Editor ed.^eds.). City: Australian Institute of Health and Welfare, Cat. no. AUS 99

28. Jones R, Furze G, Buckley J, Speck L, Carver C, Connolly S, Todd I, Wells CA, Mills J, Traill J, Aphramor L, Begg B, Doherty P, MacCallum A: RAMIT presents an outdated version of cardiac rehabilitation. Heart 2012, 98:672. doi:610.1136/heartjnl-2012-301766.
29. Neubeck L, Redfern J, Fernandez R, Briffa T, Bauman A, Freedman SB: Telehealth interventions for the secondary prevention of coronary heart disease: A systematic review. Eur J Cardiovasc Prev Rehabil 2009, 16:281-289

30. Krishna S, Boren S, Balas E: Healthcare via cell phones: a systematic review. Telemed Journal E Health 2009, 15:231-240.

31. Fjeldsoe BS, Marshall AL, Miller YD: Behavior change interventions delivered by mobile phone telephone short-message service. Am J Prev Med 2009, 36:165-173.

32. Free C, Phillips G, L G, Felix L, Edwards P, Patel V, Haines A: The effectiveness of mobile-health technology-based health behaviour change or disease management for health care consumers: A systematic review. PLOS Med 2013, 10:e1001362.

33. Jones KR, Lehak N, Kaewluang N: Using mobile phones and short message service to deliver interventions for chronic conditions: A meta review. Worldviews Evid Based Nurs 2014. doi:10.111/wvn.12030.

34. Maddison R, Pfaeffli L, Whittaker R, Stewart R, Kerr AJ, Jiang A, Kira G, Leung W, Dalleck L, Carter KH, Rawstorn J: A Mobile Phone Intervention Increases Physical Activity in People with Cardiovascular Disease: Results from the HEART Randomised Controlled Trial. Eur J Prev Cardiol 2014, May 9. doi:10.1177/2047487314535076

35. Pfaeffli L, Maddison R, Whittaker R, Stewart R, Kerr A, Rawstorn J, Carter KA: Using Mobile Technology to Deliver Exercise-based Cardiac Rehabilitation: Participant Perspectives from the HEART Trial. In Book Using Mobile Technology to Deliver Exercise-based Cardiac Rehabilitation: Participant Perspectives from the HEART Trial. (Editor ed.^eds.). City; 2013.

36. Worringham C, Rojek A, Stewart I: Development and feasibility of a smartphone, ECG and GPS based system for remotely monitoring exercise in cardiac rehabilitation. PLOS ONE 2011, 6:e14669.

37. Chan A-W, Tetzlaff JM, Gøtzsche PC, Altman DG, Mann H, Berlin JA, Dickersin K, Hróbjartsson A, Schulz KF, Parulekar WR, Krleža-Jerić K, Laupacis A, Moher D: SPIRIT 2013 explanation and elaboration: guidance for protocols of clinical trials. BMJ 2013, 346:e7586.

38. Chan A-W, Tetzlaff JM, Altman DG, Laupacis A, Gøtzsche PC, Krleza-Jeric K, Hróbjartsson A, Mann H, Dickersin K, Berlin JA, Doré CJ, Parulekar WR, Summerskill WSM, Groves T, Schulz KF, Sox HC, Rockhold FW, Rennie D, Moher D: SPIRIT 2013 Statement: Defining Standard Protocol Items for Clinical Trials. Ann Intern Med 2013, 158:200-207.

39. Eysenbach G: CONSORT- EHEALTH: Improving and Standardizing Evaluation Reports of Web-based and Mobile Health Interventions. J Med Internet Res 2011, 13:e126.

40. U.S. Department of Health \& Human Services: Physical Activity and Health: A report of the Surgeon General. In Book Physical Activity and Health: A report of the Surgeon General. (Editor ed.^eds.). pp. 137. City: U.S. Department of Health \& Human Services, Centres of Disease Control and Prevention, National Center for Chronic Disease Prevention and Health Promotion; 1996:137.

41. Kavanagh T, Mertens DJ, Hamm LF, Beyene J, Kennedy J, Corey P, Shephard $\mathrm{RJ}$ : Prediction of long-tern prognosis in 12169 men referred for cardiac rehabilitation. Circulation 2002, 106:661-671.

42. Kavanagh T, Mertens DJ, Hamm LF, Beyene J, Kennedy J, Corey P, Shephard $\mathrm{RJ}$ : Peak oxygen inatke and cardiac mortality in women referred for cardiac rehabilitation. J Am Coll Cardiol 2003, 42:2139-2143.

43. Altman DG, Bland JM: Measurement in Medicine: the analysis of method comparison studies. The Statistician 1983, 32:301-317.

44. American College of Sports Medicine: ACSM'S Guidelines for Exercise Testing and Prescription. 8th edition. Baltimore: Lippincott; 2009.

45. Borg G: Borg's perceived exertion and pain scales. Champaign, Illinois: Human Kinetics; 1998.

46. Warren I, Weerasinghe T, Maddison R, Wang Y: OdinTelehealth: A Mobile Service Platform for Telehealth. Procedia Computer Science 2011, 5:681-688.

47. Bandura A: Self-Efficacy: The exercise of control. New York: W.H. Freeman and Company; 1997.

48. Blanchard CM, Rodgers W, Courneya KS, Bill D, Knapik G: Does barrier efficacy mediate the gender-exercise adherence relationship during phase II cardiac rehabilitation. Rehabil Psychol 2002, 47:106-120.

49. Norton K, Olds T: Anthropometrica. Sydney, Australia: University of New South Wales Press; 1996

50. McAuley E, Mihako SL: Measuring Exercise-Related Self-Efficacy. In Advances in Exercise Psychology Measurement. Edited by Duda JL. Morgantown: Fitness Information Technology, Inc; 1998:371-389. 
51. Constructing a TPB questionnaire: Conceptual and Methodological Considerations [http://people.umass.edu/aizen/pdf/tpb.measurement.pdf]

52. Markland D: Self-determination moderates the effects of perceived competence on intrinsic motivation in an exercise setting. J Sport Exerc Psychol 1999, 21:351-361.

53. Godin G, Shephard RJ: Godin Leisure-Time Exercise Questionnaire. Med Sci Sports Exerc 1997, 29 June Supplement:S36-S38.

54. Healy GN, Matthews CE, Dunstan DW, Winkler EA, Owen N: Sedentary time and cardio-metabolic biomarkers in US adults: NHANES 2003-06. Eur Heart J 2011, 32:590-597.

55. Van Remoortel H, Raste Y, Louvaris Z, Giavedoni S, Burtin C, Langer D, Wilson F, Rabinovich R, Vogiatzis I, Hopkinson NS, Troosters T: Validity of six activity monitors in chronic obstructive pulmonary disease: a comparison with indirect calorimetry. PLoS One 2012, 7:e39198.

56. Mâsse L, Fuemmeler BF, Anderson CB, Matthews CE, Trost S, Catellier DJ, Treuth MS: Accelerometer data reduction: A comparison of four reduction algorithms on select outcome variables. Med Sci Sports Exerc 2005, 37:S544-S554.

57. EQ-5D: A standardised instrument for use as a measure of health outcome. http://www.eurogol.org/euroqol-group/about-us.html.

58. Schumi J, Wittes JT: Through the looking glass: understanding non-inferiority. Trials 2011, 12:106.

59. Martin B, Arena R, Haykowsky M, Hauer T, Austford L, Knudtson M, Aggarwal S, Stone J: Cardiovascular fitness and mortality after contemporary cardiac rehabilitation. Mayo Clin Proc 2013, 88:455-463.

doi:10.1186/1471-2458-14-1236

Cite this article as: Maddison et al:: The remote exercise monitoring trial for exercise-based cardiac rehabilitation (REMOTE-CR): a randomised controlled trial protocol. BMC Public Health 2014 14:1236.

\section{Submit your next manuscript to BioMed Central and take full advantage of:}

- Convenient online submission

- Thorough peer review

- No space constraints or color figure charges

- Immediate publication on acceptance

- Inclusion in PubMed, CAS, Scopus and Google Scholar

- Research which is freely available for redistribution 